\title{
SOCIOLOGIA ECONÔMICA E COMPETITIVIDADE EM COOPERATIVAS AGROPECUÁRIAS CENTRALIZADAS
}

\author{
Economic Sociology and Competitiveness in Centralized Agricultural Cooperatives
}

\begin{abstract}
RESUMO
A gestão de empreendimentos cooperativos centralizados do setor agropecuário é marcada por grande complexidade. No presente trabalho, de natureza teórica, visou-se a discorrer, à luz das três correntes epistemológicas da Sociologia Econômica - Redes, Institucionalismo em sua vertente econômica e Teoria dos Campos -, a forma pela qual poderia se compreender a busca pela competitividade em cooperativas agropecuárias de segundo grau. A análise apegou-se na extrapoção de cada dos condicionantes constitutivos das bases epistemológicas da Sociologia Econômica. Enquanto a perspectiva das Redes garantiria a viabilidade econômica do negócio, por meio do adensamento do capital social, o Institucionalismo conformaria uma formalização contratual para a redução dos custos de transação, e a perspectiva dos Campos atuaria na constituição de um poder simbólico resultante de uma habilidade estratégica do agente sob a estrutura. Concluí-se que a perspectiva pela qual a ação social resulta em resultados econômicos às cooperativas agropecuárias centralizadas, é passível de ser analisada sob três enfoques teóricos em que a cada um haverá fatores intervenientes distintos, tanto ao problema quanto em relação à compreensão dos resultados.
\end{abstract}

Gustavo Leonardo Simão

Universidade Federal de Viçosa

gustavo.simão@ufv.br

Luiz Marcelo Antonialli

Universidade Federal de Lavras

Imantonialli@ufla.br

Alex dos Santos Macedo

Universidade Federal de Viçosa

alexmacedo.ufv@gmail.com

Antônio Carlos dos Santos

Universidade Federal de Lavras

acsantos@ufla.br

Recebido em: 21/09/2016. Aprovado em: 16/01/2019.

Avaliado pelo sistema double blind review

Doi: 10.21714/2238-68902018v20n2p088

\begin{abstract}
The management of centralized cooperative enterprises in the agricultural sector has been marked by great complexity. This theoretical study aimed to discuss, in the light of the three epistemological currents of the Economic Sociology - Networks, Institutionalism in its economic aspect and Field Theory - the way to understand the search for competitiveness in agricultural centralized cooperatives. The analysis remained in the extrapolation of each one of the constituents of the epistemological foundations of Economic Sociology. While the Networks perspective ensure business economic viability by consolidation of the social capital, the Institutionalism focuses in contractual formalization to reduce transactional costs, and the Fields perspective look in the symbolic power, reached an maintained by the strategic skill of the agent on the structure. We conclude that the perspective by which economic results will be obtained as a result of social actions in centralized agricultural cooperatives context is likely to be analyzed under three theoretical approaches, in which each will have different factors involved, in relation to the understanding of the results.
\end{abstract}

Palavras-chave: Cooperativismo, Epistemologia, Gestão.

Keywords: Cooperativism, Epistemology, Management.

\section{INTRODUÇÃO}

Os empreendimentos cooperativos do setor agropecuário, caracterizados como organizações complexas, têm incorporado novas tendências competitivas, notavelmente em relação às perspectivas de integralização e verticalização, criando cooperativas centrais. É por meio da centralização que as cooperativas conseguiriam incrementar sua cadeia de valor que, na maior parte das vezes, é composta por commodities, típicas das cooperativas singulares. Essa tendência seria uma alternativa para aumentar as vantagens competitivas do negócio cooperativo frente à crescente concentração de mercado de empresas não cooperativas. 
Quanto maior for a cadeia de valor das cooperativas agropecuárias, maior também será a complexidade de sua gestão. O empreendimento centralizado assume uma maior responsabilidade na coordenação da cadeia produtiva quanto aos aspectos de eficiência e eficácia, tanto em relação à disponibilização de produtos competitivos quanto na satisfação do quadro social que compõe as cooperativas singulares. Além disso, o processo de integração vertical, advindo da centralização do empreendimento cooperativo, tende a aumentar a distancia relacional entre os produtores rurais associados nas cooperativas singulares e os tomadores de decisão, que se concentram na cooperativa central.

Em razão da sua natureza, as cooperativas são caracterizadas como organizações de pessoas, com fortes aspectos doutrinários relacionados às suas especificidades sociais. Seria, dessa forma, um empreendimento cujos resultados econômicos resultariam das relações sociais entre os membros que nela se encontram.

A Sociologia Econômica toma, nesse contexto, uma aplicabilidade consideravelmente plausível, como corrente teórica para a análise do contexto complexo do cooperativismo, como perspectiva sociológica, e também da perspectiva econômica das cooperativas singulares e de suas associações para a formação de empreendimentos de segundo grau.

No presente artigo, de natureza teórica, objetivouse analisar a tendência de competitividade, ou obtenção de competitividade, das cooperativas agropecuárias centralizadas à luz da Sociologia Econômica sob o enfoque dos três principais paradigmas que nela se situam, quais sejam: Redes; Nova Economia Institucional (Institucionalismo); Teoria dos Campos. Dessa forma, pretende-se garantir às futuras incursões empíricas, cujo foco se paute pela análise da competitividade no âmbito de cooperativas agropecuárias centrais, delimitações teóricas a fim de clarificar o enfoque epistemológico dessas pesquisas, oferecendo os principais pontos de cada uma das perspectivas.

Diante do desafio proposto, o trabalho encontra-se dividido em três tópicos principais, além desta introdução. O tópico seguinte ao contexto introdutório externa as peculiaridades de gestão do empreendimento cooperativo, com destaque para cooperativas de segundo grau, também denominadas de cooperativas centrais. $\mathrm{O}$ terceiro tópico discorre acerca da visualização teórica de cada uma das perspectivas elencadas no cerne da Sociologia Econômica, especificamente em relação ao entendimento dos mecanismos estruturais intervenientes à competitividade em cooperativas centrais. Por fim, o terceiro tópico aponta para as digressões finais obtidas a partir das reflexões delineadas ao longo do trabalho.

\section{A COOPERATIVA VISTA COMO UM SISTEMA COMPLEXO DE GESTÃO}

Apesar da importância social que os empreendimentos cooperativos apresentam, Bialoskorski Neto (2008) ressalta que essas organizações têm, e devem ter preocupações econômicas. Diante dessas afirmações, Emelianoff (1942) e Boland et al. (2011) caracterizam as cooperativas agropecuárias como a integração das unidades econômicas de seus associados. Os empreendimentos cooperativos, no setor agropecuário, nessa perspectiva, seriam criados para a agregação de vantagens competitivas ao quadro de seus associados, que separadamente apresentam desvantagens econômicas frente ao contexto de operação do agronegócio.

Valadares (2005) aponta para dois cenários econômicos principais existentes às organizações cooperativas (Figura 1). O cenário 1, considerado interno, caracteriza-se pela relação existente entre a cooperativa e o cooperado, sendo balizado pela necessidade do empreendimento cooperativo disponibilizar ambientes favoráveis à viabilização das unidades econômicas dos associados, tornando-as competitivas ${ }^{1}$. O cenário 2 , considerado externo, remete-se à relação entre a cooperativa e o mercado, externando uma necessidade de níveis competitivos que assegurem viabilidade econômica ao empreendimento que, nesse contexto, é percebido como uma firma qualquer e que, por isso, há de ser competitiva.

Ademais, a natureza da participação do associado é, na maioria das vezes, conflitante. Há uma despersonificação da figura do associado, haja vista que a figura de cliente, fornecedor, gestor e proprietário estão concentrados, por vezes, em uma única pessoa. Há, portanto, uma latente incompatibilidade de expectativas no negócio cooperativo, que se amplia na medida em que todos esses cenários são extrapolados às relações de cooperativas singulares com a cooperativa de segundo grau em processos de centralização ${ }^{2}$.

O processo de elaboração de estratégias, voltadas à competitividade do empreendimento pluralista ${ }^{3}$ deve considerar o problema da multiplicidade de anseios que são simultaneamente conflitantes à elaboração do

${ }^{1}$ Competitividade, neste trabalho, diz respeito ao estabelecimento pelas cooperativas agropecuárias de "uma posição lucrativa e sustentável contra as forças que determinam a competição industrial” (PORTER, 1992, p.1).

${ }^{2}$ Levi e Davis (2008) por este contexto caracterizam as cooperativas como uma "enfant terrible" dada sua contraditória despersonalização.

${ }^{3}$ Organizações pluralistas são assim denominadas quando possuem interesses e objetivos divergentes entre os grupos que as compõem, sendo que cada um desses apresentam prerrogativas para garantir que seus objetivos sejam legitimados na estratégia da organização (JARZABKZOWSKI e FENTON, 2006). 
planejamento do negócio (JARZABKOWSKI; FENTON, 2006). A complexidade torna-se evidente, na medida em que esses múltiplos objetivos têm de serem considerados. Boland et al (2011) ressaltam que uma cooperativa somente obterá sucesso econômico, a partir de um planejamento estratégico que esteja alinhado aos de seus associados.

Tal alinhamento perpassa invariavelmente pelas características sociais do empreendimento. Crúzio (1999), Antonialli (2000) e Gimenes e Gimenes (2007) acreditam que algumas características distintivas do empreendimento cooperativo, notavelmente os relacionados aos princípios dogmáticos (gestão democrática, falta de gestão profissionalizada, dentre outros) tornam o processo de decisão mais lento e, portanto, menos competitivo. Tais características comprometeriam os setores de marketing, inovação, pesquisa e desenvolvimento e planejamento futuro do negócio.

Diante dessas particularidades, as cooperativas agropecuárias podem se apresentar sob distintas formas estruturais. As cooperativas agropecuárias singulares, ou locais, na terminologia adotada por Cook (1995), são representadas, na maioria das vezes, pela comercialização de commodities agrícolas com pouca agregação de valor, com atuação local e quadro de associados homogêneo.

Contudo, o contexto globalizado do agronegócio tem sido marcado por uma grande intensidade competitiva. Organizações locais passam, cada vez mais, a competir com empresas multinacionais que, pelo volume de produção inviabiliza economicamente a atuação das cooperativas tradicionais, que possuem capacidade produtiva para atuação limitada ou apenas nas primeiras etapas do sistema agroalimentar (HARTE, 1997). Isso se deve ao aumento do grau de industrialização na agricultura primária, introdução de novas tecnologias e a adoção de novas formas de gestão (AMODEO, 2001; GIMENES; GIMENES, 2007; NILSSON et al., 2012).

Tal contexto faz com que a tendência competitiva das cooperativas agropecuárias aponte para a representação de outra face do negócio cooperativo. Nesse caso, as cooperativas seguem uma linha de verticalização e integralização criando cooperativas centrais que passam a agregar valor aos produtos disponibilizados pelas cooperativas singulares associadas (TORGERSON, 2001). Assim, a cooperativa criaria condições de competir com organizações não cooperativas, dado seu portfólio de atuação, uma vez que os preços pagos aos associados poderiam ser maiores e os custos de produção mais baixos. Diversos pesquisadores apontam que esta é a principal tendência competitiva para as cooperativas agropecuárias, ou seja, o crescimento baseado na verticalização e na integralização de pequenas cooperativas em empreendimentos cooperativos centrais (GALERANI, 2003; MAGALHÃES, 2007; LING, 2011; BIALOSKORSKI NETO, 2012; NILSON et al. 2012).

Por outro lado, todas as etapas da cadeia de valor seriam parte da cooperativa, quando a estratégia for a centralização e integralização mediante a ampliação do negócio cooperativo, e teriam assim de ser geridas, por meio dos princípios ideológicos e doutrinários do cooperativismo. Esses princípios ensejam que as decisões

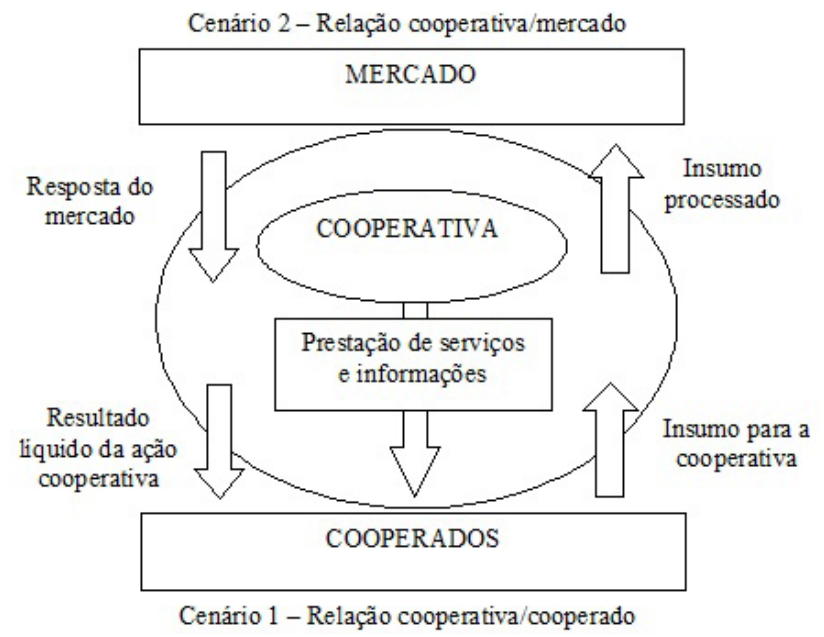

FIGURA 1 - Modelo teórico das relações econômicas em cooperativas agropecuárias Fonte: Valadares, 2005

Organizações Rurais \& Agroindustriais, Lavras, v. 20, n. 2, p. 88-100, 2018 
sejam democráticas, participativas e amplamente discutidas pelas cooperativas singulares. Há, portanto, um contexto aparentemente contraditório, pois, a tendência para que o empreendimento cooperativo seja mais competitivo (rápida tomada de decisão, preços competitivos pagos aos insumos recebidos dos "fornecedores", dentre outros), aparentemente atua em sentido oposto aos princípios do cooperativismo, uma vez que eles podem ser menos influentes nesse cenário.

Nassar e Zylbersztajn (2004) evidenciam, por meio de estudos empíricos que o associativismo interposto em grupos grandes apresenta, na maioria das vezes, quadros heterogêneos, uma complexidade maior no tocante à gestão e na obtenção de uma estratégia que represente o interesse de todos os agentes. O que também corrobora o posicionamento de Ôsterberg e Nilsson (2009), onde se afirma que cooperativas operando em grandes áreas geográficas possuem associados em condições adversas, $\mathrm{o}$ que pode representar interesses distintos e conflitantes. Tal contexto pode acarretar a perda de identidade do associado para com o empreendimento, gerando uma situação de passividade.

Em suma, a competitividade do empreendimento cooperativo agropecuário defronta-se com uma aparente contradição, por um lado advoga pela necessidade de integralização e verticalização, constituindo empreendimentos robustos e com atuação ao longo da cadeia de valor dos produtos agropecuários. Por outro lado, esse processo tende a criar cenários de desgaste no engajamento entre os membros associados e, por consequência, uma diminuição nos incentivos à sua permanência e/ou participação na organização. Esse contexto de relações sociais incrustado nas relações de mercado (econômicas), necessárias à perenidade do empreendimento cooperativo, é passível de ser explicada a partir de algumas perspectivas da vertente teórica da Sociologia Econômica.

\section{A SOCIOLOGIA ECONÔMICA E SEUS DISTINTOS OLHARES À COMPETITIVIDADE NAS COOPERATIVAS AGROPECUÁRIAS CENTRAIS}

A Sociologia Econômica defende os pressupostos de que, ao contrário da visão neoclássica da economia, permeada pelo individualismo metodológico, da racionalidade e da visão atomizada dos atores, as relações sociais acarretam implicações nas relações econômicas. Segundo Beckert (1996, p. 803), a Sociologia Econômica lida com "as relações sociais, cultura, cognição, normas, estruturas, poder e instituições sociais como variáveis explicativas para a interpretação de resultados econômicos". Essas perspectivas seriam vistas sob três enfoques: a perspectiva das Redes, a vertente Institucionalista e a Teoria dos Campos (SACOMANO NETO; TRUZZI, 2009).

\subsection{O Enfoque das Redes}

O processo de integralização e verticalização das cooperativas agropecuárias, voltado ao incremento de níveis competitivos, pode ser explicado à luz do enfoque das redes, conceituada como as alianças de partilha e codesenvolvimento existentes entre organizações para lidar com as incertezas das forças ambientais (GULATI, 1999). Assim, no caso das cooperativas agropecuárias, criar-se-ia uma conexão densa de relacionamentos (closure) fortalecendo o capital social, o que facilitaria o processo de inovação, aumentando a confiança e a reciprocidade entre seus membros (AHUJA, 2000; BURT, 2001; VALE et al. 2006; NOVKOVIC; HOLM, 2012).

A formação de redes intercooperativas tenderia a favorecer maiores níveis de capital social (PORTES, 1998; GRANOVETTER, 2000). Contudo, não basta constituir um empreendimento integralizado em diversos níveis para o surgimento de uma rede. Amodeo (2001) ressalta que, no caso das cooperativas, as redes deveriam utilizar de suas densas e privilegiadas relações com seus sócios para traçar suas propostas estratégicas, e não o contrário, sob pena de suplantar seus ideais de identidade cooperativa ${ }^{4}$ e, com isso, definhar a identidade do sócio, ou das cooperativas sócias, para com o negócio. O fortalecimento das redes intercooperativas passa pelo que Granovetter (1990) denominou de embeddedness (imersão).

Segundo Granovetter (1990), a imersão diz respeito às relações sociais existentes em determinadas estruturas, por meio dos atores que nela se encontram, inclusive nas redes interorganizacionais, que acarretam efeitos de confiança e, por consequência, diminuição de comportamentos oportunistas. A visão da imersão tende a defender que a realização de transações com organizações e atores já conhecidos é mais favorável a arriscar-se livremente no mercado. Além disso, as redes interorganizacionais seriam estruturas que, mediante densas relações sociais entre os atores, favoreceria maiores níveis de competitividade, na medida em que tornariam as informações mais baratas, precisas e seguras.

${ }^{4} \mathrm{~A}$ identidade cooperativa está relacionada aos princípios da ajuda mutua, gestão democrática, e os demais valores cooperativos. 
No caso das cooperativas agropecuárias centralizadas, pode-se dizer que os efeitos econômicos da imersão, com reflexos na competitividade do empreendimento, estariam subdivididos em dois estágios ou em relações de duas ordens distintas, conforme evidencia-se na Figura 2.

As relações de $1^{\mathrm{a}}$ ordem ocorrem entre o produtor rural e a cooperativa singular a qual ele é associado. Nesse contexto, a criação de vínculos sociais entre ambos, com o adensamento dos níveis de capital social, facilitaria a intermediação dos questionamentos do fornecedor de insumos (produtor rural) junto à cooperativa central. Suponha-se que o associado, produtor de leite, entregue sua produção diretamente à cooperativa central, contudo, esteja insatisfeito com os preços pagos. Como a relação social desse associado com a cooperativa singular é, na maioria dos casos, mais densa, este leva seu questionamento à mesma para que esta tome providências junto à cooperativa central. Essa relação de $1^{\mathrm{a}}$ ordem contribui, dentre outros fatores, para o processo de imersão da rede, uma vez que o produtor rural, como no exemplo acima, é menos voltado a fazer negócios com outros compradores, haja vista que tem uma reputação a zelar junto a seus pares, filiados na cooperativa singular. Tal reputação, contudo, só ocorre quando os níveis de capital social são suficientemente densos.

A relação de $2^{\mathrm{a}}$ ordem ocorre justamente a partir dos efeitos gerados pelas relações de $1^{\circ}$ grau. Quando o representante da cooperativa singular leva seus questionamentos à cooperativa central, há uma tendência de se tentar resolvê-lo, uma vez que, naquele espaço, o representante da cooperativa singular atua como mandatário dos anseios daqueles produtores rurais associados à cooperativa singular, mas também como agente auxiliar na tomada de decisão do empreendimento central. Caso não ocorra a resolução de tal ponto conflituoso poderá não só haver um abalo na relação de $1^{\circ}$ grau, mas igualmente no enlace de $2^{\circ}$ grau. Por consequência, poderá existir uma ruptura da relação do produtor rural com a cooperativa singular, o que não é interessante ao seu presidente que geralmente representa a cooperativa sócia junto à cooperativa central. Por isso, a necessidade de manutenção da rede.

As relações de $1^{\mathrm{a}}$ e $2^{\mathrm{a}}$ ordem formam o que, aqui, denomina-se de processo de imersão das relações sociais totais existentes na integralização de cooperativas agropecuárias, por meio do processo de centralização. As redes relacionais e interorganizacionais de ambas as ordens seriam eficazes, na medida em que atuariam como fontes de pressão, uma vez que nem sempre os objetivos de ambos os empreendimentos (cooperativa singular e central) situam-se em um mesmo sentido, mas qualquer dano a qualquer um dos enlaces de ambas as relações pode prejudicar a perenidade de todo a estrutura.

$\mathrm{O}$ modelo federado de cooperativas requer uma forma adequada de estruturar os fluxos de informações, frente à dificuldade em articular os interesses de produção primária de grande número de produtores, da organização produtiva por parte das Cooperativas singulares, juntamente com os interesses agroindustriais da Central (SOUZA et al., 2011).

Essa forma de regulação dos fluxos de informação e relação poderia ser resultante, conforme já discorrido, da imersão estrutural total da rede interorganizacional. Quando o processo é constituído por meio de relações duplamente significativas ocorre a formação de relações sociais mais densas, haja vista que os atores estão proximamente relacionados. Isso ocorre, uma vez que as cooperativas singulares operam em favor da constituição de relações confiáveis junto à central, evitando o que

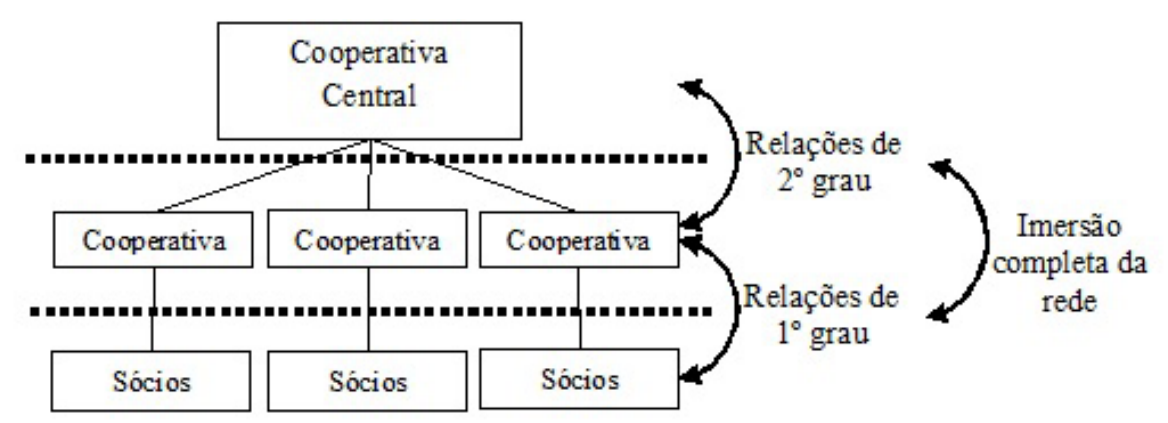

FIGURA 2 - Representação esquemática das relações sociais de imersão em rede de cooperativas Fonte: elaboração própria, a partir de Granovetter (1990)

Organizações Rurais \& Agroindustriais, Lavras, v. 20, n. 2, p. 88-100, 2018 
Chaddad (2007) denominou de atritos e divergências políticas, sem eliminar os ganhos competitivos da entrega dos produtos agrícolas de seus associados diretamente à cooperativa central.

A competitividade de um sistema integralizado de cooperativas deverá levar em consideração a forma como a rede é centralizada, quais são os principais contatos externos e internos que podem tornar o processo mais viável, qual a proximidade e similaridades dos negócios, dentre outros. Tudo isso se encontra no âmbito de uma análise estrutural, que deve ser considerada prioritária sob essa perspectiva. Na questão do conteúdo, este se voltará a definir o teor a ser repassado nos laços elencados na estrutura da rede, que são compostos por questões tangíveis (produtos e serviços) e intangíveis (informações, questões emocionais, reputação, dentre outros).

Todavia, alguns apontamentos negativos também são passíveis de serem explicados pela abordagem das redes interorganizacionais, inclusive no caso das cooperativas de segundo grau. Granovetter (1990) ressalta que atitudes desonestas podem surgir, uma vez que os ganhos de atitudes oportunistas são diretamente proporcionais aos níveis de confiança existentes. O surgimento do oportunismo, contudo, dependerá, ressalta o referido autor, da forma como a rede estiver e vier a ser estruturada. Por isso, propõe-se que a competitividade só será duradoura a partir da criação de laços fortes junto às duas ordens apontadas.

\subsection{O Enfoque do Institucionalismo a partir da Nova Economia Institucional (NEI)}

O chamado Novo Institucionalismo ${ }^{5}$ abrange diversos enfoques e, por isso, foi classificado por alguns pesquisadores em três grandes contextos: o sociológico, histórico/político e o econômico (HALL; TAYLOR, 1996; THELEN, 1999; THÉRET, 2003). Para os fins propostos neste trabalho analisar-se-á o Institucionalismo em sua vertente econômica, a partir disso o foco se aterá à forma de como essa vertente pode contribuir na compreensão dos cenários competitivos junto às cooperativas agropecuárias integralizadas.

Hall e Taylor (1996) explicam que a perspectiva econômica desse novo Institucionalismo é especialmente relevante para apontar como a Abordagem Institucional

${ }^{5} \mathrm{Na}$ perspectiva da Nova Economia Institucional (NEI), as instituições, entendidas como as regras formais e informais, costumes e acordos são os responsáveis diretos pelo desempenho econômico, tanto das sociedades, quanto das diversas organizações que nela se situam (NORTH, 1994). pode auxiliar na redução de determinados custos organizacionais, denominados de custos de transação. Esses custos de transação tenderiam a declinar por uma estrutura de governança adequada. Estrutura essa que seria alcançada principalmente no monitoramento das relações contratuais entre os diversos atores envolvidos em determinado ambiente institucional, a fim de zelar pelo cumprimento das regras sociais esperadas. Zylbersztajn (2002), Valadares (2003) e Bialoskorski Neto (2012) reconhecem as cooperativas como arranjos institucionais complexos em virtude das relações existentes entre os diversos agentes que, com, mantêm contato. Aliado à figura dos variados agentes somam-se a materialização de arcabouços legais e doutrinários.

Em seu trabalho seminal, Coase (1937) ressaltou que uma firma só obterá resultados econômicofinanceiros viáveis à sua perenidade na medida em que otimizar suas transações, por meio de uma estrutura de governança adequada. Tais transações, conforme se percebe, não se resumem àquelas destacadas pela economia neoclássica (trocas financeiras), são mais abrangentes e se relacionam a toda e qualquer troca onde um ou mais atores transacionam bens, serviços e informações (WILLIAMSON, 1991).

O monitoramento da consecução favorável desse emaranhado de transcoes acarretam custos que só serão dirimidos a partir de uma adequada gestão e estruturação dos empreendimentos frente ao ambiente institucional. Discorrendo sobre as principais perspectivas intervenientes à ascensão de tais custos, Amodeo (1999) afirma que quanto maior a especificidade dos ativos de determinada cooperativa, maior também serão as chances de comportamentos oportunistas, não somente pelos associados, mas por todos os stakeholders.

Na visão de Coase (1937), a gestão de tais custos dá-se pela concepção inicial da assunção da perspectiva contratual. Por essa visão, uma firma seria vista como um nexo de contratos. Tais contratos seriam firmados entre os mais diversos atores que com a firma se relacionam, inclusive em relações aos seus associados ${ }^{6}$.

$\mathrm{O}$ adequado entendimento da relação contratual da relação do associado para com o empreendimento cooperativo e deste para com os demais atores, e seu posterior monitoramento, contribuiriam para a redução

${ }^{6}$ Bialoskorski Neto (2008, p. 17) afirma que a NEI e a ECT assume "que a empresa é um arranjo de contratos estabelecidos entre a direção e seus funcionários, entre a empresa e seus fornecedores, entre a empresa e seus clientes, entre os gestores e os proprietários desta empresa, entre outros". 
dos custos transacionais favorecendo a otimização dos níveis competitivos do empreendimento.

Consenso sob essa perspectiva é que, além de observar os custos de produção, a cooperativa central teria também que monitorar os seus custos de transação em seus diversos nexos contratuais ${ }^{7}$ existentes. Isso, conforme já adiantado, só seria possível a partir de um entendimento da estruturação do empreendimento (arranjo organizacional), e a partir de tal entendimento, de uma gestão de governança adequada à redução de custos transacionais.

$\mathrm{Na}$ Figura 3, evidencia-se o ambiente institucional de uma cooperativa integralizada à luz da NEI, onde as ligações pontilhadas representam as relações contratuais que podem ser formais ou informais. Ademais, verificase, esquematicamente a miscigenação de tipologias de governança envolvidas nesse complexo ambiente institucional.

A eficácia na gestão dos contratos da cooperativa central, inclusive em relação à sua eficiência econômicofinanceira, estaria diretamente atrelada ao entendimento dos pontos diferenciadores do arranjo organizacional no tocante à delimitação das perspectivas de governança interveniente ao negócio. Assume-se, nesse sentido, que a cooperativa agropecuária centralizada se apresenta

${ }^{7} \mathrm{O}$ presente esquema representativo não visou exaurir as relações contratuais existentes no contexto das cooperativas centrais, mas representar aqueles mais expressivos. como agente de transação em diferentes estruturas de governança.

Na percepção de Williamson (1991) existiriam três formas básicas de governança passíveis de representarem as relações contratuais, quais sejam: governança de mercado, hierárquica e híbrida. Infere-se que todas podem ser compreendidas no complexo ambiente institucional das cooperativas centrais.

A estrutura de governança de mercado corresponderia às transações da cooperativa central com os diversos atores a ela externamente relacionados tais como os fornecedores, o governo e as cooperativas singulares. Destaque ao fato de que, nesse caso, ou seja, no contexto agropecuário, em que o empreendimento centralizado industrializa commodities, as cooperativas singulares são entendidas na imbricação de dois cenários (governança de mercado e hierárquica). Enquanto pertencentes ao contexto da governança de mercado entende-se que, pelo fato de haver baixa especificidade dos ativos, no tocante aos insumos necessários à industrialização, a cooperativa central não teria dificuldades, em caso de recusa de entrega ou entrega abaixo do esperado, em adquirir tais insumos em transações de mercado com terceiros não ligados ao seu quadro social.

A governança hierárquica corresponde ao contexto pelo qual a cooperativa central se relaciona com as cooperativas singulares, e estas, com seus diversos associados, uma vez que, nesse processo, há interdependências transacionais formalmente constituídas.

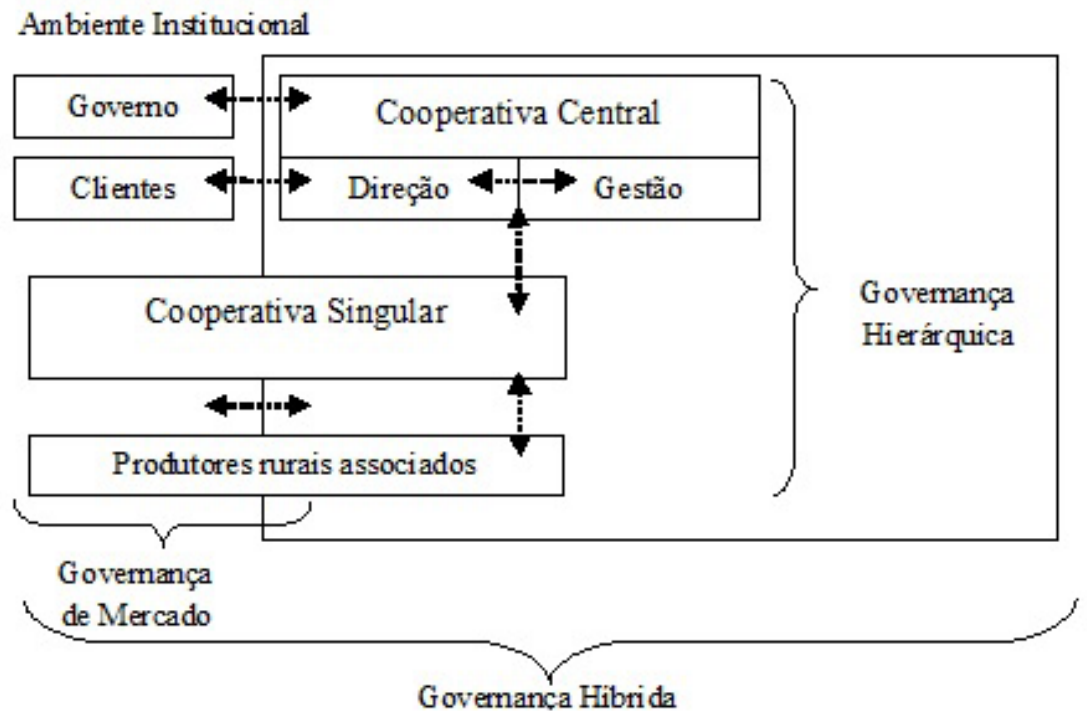

FIGURA 3 - Representação esquemática das relações contratuais de uma cooperativa integralizada Fonte: elaboração própria, a partir de Coase (1937); Williamson (1999); Chaddad; Iliopoulos (2013)

Organizações Rurais \& Agroindustriais, Lavras, v. 20, n. 2, p. 88-100, 2018 
Ao passo que as cooperativas singulares subscrevem capital para participarem como sócias do empreendimento centralizado e, igualmente, os produtores rurais subscrevem capital nas cooperativas singulares, há um direito de propriedade formalizado gerador de interdependência. Consubstancia-se, portanto, a emersão de uma estrutura hierarquizada de coordenação. Decorre dessa formalização contratual a expectativa das cooperativas singulares transacionarem os insumos apenas com a cooperativa central, por isso também caracterizada sob a ótica hierárquica. Há, nessa ótica, o pressuposto da garantia da coordenação das relações existentes voltadas ao fim último da redução dos custos de transação.

E, por fim, a forma híbrida, seria a junção das formas anteriores, ou seja, quando o empreendimento mantêm relações de mercado e hierárquicas. Na perspectiva de Ménard (2006), tal concepção estaria atrelada quando se torna passível a identificação de três condicionantes, quais sejam: agrupamento de recursos (concordância na perda de autonomia ocasionada pela governança hierárquica), coordenação por contratos para a criação de um framework conjunto (formalização contratual), e quando há a combinação de cooperação/competição.

Uma das perspectivas contemporâneas que torna evidente a materialização da condição híbrida das cooperativas agropecuárias é quando se abre a possibilidade de a cooperativa captar recursos de agentes externos ao seu quadro social emitindo-se ações, ou também na preceituada governança cooperativa em que se advoga pela necessidade de inserção de gestores contratados, externos ao quadro social, para auxiliarem na tomada de decisão do negócio. Todas essas "inovações" são passiveis de serem percebidas na chamada Nova Geração de Cooperativas (NGC).

Observa-se diante dos argumentos expostos até o momento, que a NEI traz diversas contribuições para a compreensão do empreendimento cooperativo centralizado, elucidando soluções, por meio de formalizações (nexos contratuais), dos direitos de propriedade e da necessidade da redução dos custos de transação, tanto entre as cooperativas singulares e central, das singulares com seus associados e de ambas as organizações com seus diversos stakeholders.

Entretanto, mesmo apontando para algumas soluções, Amodeo (1999) ressalta que nem todas as ações em um empreendimento cooperativo tradicional podem ser reduzidas a relações contratuais, destacadamente em relação aos princípios doutrinários que não devem ser relegados. "Não parece que esta teoria [NEI] permita fazer a diferença entre a relação 'cooperado - cooperativa' e 'produtor
- empresa não cooperativa', perdendo assim muitos dos elementos fundamentais que moldam e fazem mais difíceis as relações nessas organizações"(Idem, 1999, p. 90).

Além das especificidades doutrinárias dos empreendimentos cooperativos que a NEI tende a deixar de lado, mediante a simplificação contratual, Zylbersztajn (2002) evidencia que nem sempre os custos de agência e, por consequência, os custos de transação são dirimidos por meio de relações contratuais, formais ou informais. Segundo o referido autor, alguns dirigentes podem simplesmente se manter na direção por possuírem relações de poder dentro da cooperativa, o que segundo ele, levaria a ineficiência do empreendimento.

\subsection{A Teoria dos Campos e da Habilidade Social Estratégica}

Ao contrario da possibilidade de insucesso da perspectiva contratual externada por Zylbersztajn (2002), Fligstein (2007) vai afirmar que é justamente pelas relações de poder que se obtém sucesso no negócio. A perspectiva dos Campos se apoiará, nesse sentido, na ideia de habilidades sociais para evidenciar a manutenção e garantia da competitividade dos empreendimentos cooperativos centralizados. Cabe esclarecer como são compreendidas tais habilidades, que se perfazem a partir da ação do agente na estrutura.

Inicialmente, é preciso destacar o fato de que o enfoque dos Campos se dá por meio do poder simbólico em determinadas unidades de ordem social (BOURDIEU, 1996) ${ }^{8}$. Mesmo que as estruturas sociais internalizadas por cada uma das cooperativas singulares, por vezes pelas buscas de interesses peculiares a essas organizações, no momento da integralização, a cooperativa central tenderia a representar um poder simbólico sobrepujante.

O poder de decisão das ações do negócio cooperativo, inclusive em relação ao seu delineamento estratégico, condensado no âmbito da cooperativa central, todavia, é com frequência pressionada, seja pelos atores desafiantes representantes das cooperativas singulares, seja por técnicos gestores contratados e também por agentes externos. Tal pressão é explicada, na medida em que, na perspectiva de Fligstein e Macdam (2012), qualquer unidade social de ação coletiva seria um campo, também denominado pelos referidos autores de campo de ação estratégica. Assim, as cooperativas

\footnotetext{
${ }^{8}$ Bourdieu (1996, p. 50) define campo como um espaço de "forças [...], e como um campo de lutas, no interior do qual os agentes se enfrentam, com meios e fins diferenciados conforme sua posição na estrutura, contribuindo assim para a conservação ou a transformação da sua estrutura".
} 
singulares constituíram campos interdependentes do campo maior, que é a cooperativa central. Não somente a isso, mas qualquer segmentação social interna ${ }^{9}$ ao escopo da cooperativa central também seria percebido como um subcampo, tais como as subdivisões departamentais, unidades estratégicas de negócios pertencentes ao empreendimento cooperativo e qualquer outra.

O campo é composto por uma intensa relação de poder, onde os atores desafiantes, buscam, constantemente, que seus anseios sejam atendidos, como, por exemplo, o pagamento de maiores valores aos insumos disponibilizados à central por parte das cooperativas singulares. Por outro lado, a cooperativa central, por meio dos atores que a compõem, atuaria com seu poder dominante, uma vez que possui as melhores condições de barganha, constituindose por decorrência desse fato em agente com habilidades estratégicas voltadas à manutenção da estabilidade atual do campo. Tal atuação, todavia, deve se contrabalancear para não tornar o campo instável demais e fazer com que as cooperativas singulares decidam, mesmo com uma perda de competitividade, atuarem isoladamente (ruptura no campo organizacional da cooperativa central) (Figura 4).

$\mathrm{Na}$ Figura 7, representam-se as relações de poder existentes no empreendimento cooperativo integralizado por meio de uma cooperativa central. O sentido e a espessura das setas correlacionam o direcionamento e a força da habilidade estratégica dos atores sociais no campo, conforme apontamentos empiricamente verificados por Macedo et al. $(2013)^{10}$. Mesmo que existam alguns atores sociais atuantes na estrutura dos subcampos, no intuito de alterar a estrutura de poder vigente, enquanto o empreendimento integralizado estiver oferecendo viabilidade financeira e/ou pressão simbólica suficientemente superior, àquela exercida pelo campo ao qual o ator social desafiante esteja situado, a tendência será a manutenção da estrutura vigente, conforme ressalta Fligstein e Mcadam (2012) ${ }^{11}$.

Destarte, Bourdieu (1986) já discorria que as relações existentes nos campos, em alguns casos, são tidas como recursos usados para obter ou manter posições de poder. Esse contexto tende a explicar o motivo pelo qual diversas cooperativas integralizadas em empreendimentos centrais possuem determinados líderes, geralmente

${ }^{9} \mathrm{Há}$ também a figuração dos subcampos externos ao negócio, que para fins de simplificação não foram retratados na presente discussão.

${ }^{10} \mathrm{O}$ mencionado estudo empírico corrobora a direção e espessura das setas utilizadas no esquema da Figura 7.

${ }^{11} \mathrm{~A}$ presença de atores estratégicos hábeis em grupos ajuda a produzir e reproduzir o status quo (FLIGSTEIN e MCADAM, 2012). ocupando a posição de presidente, que se conservam no poder por longo período de tempo, e, nem por isso, o empreendimento torna-se menos competitivo. Explicaria também, os motivos pelos quais mesmo descontentes com determinados cenários traçados pela administração do empreendimento central, as cooperativas singulares não conseguiriam incrementar mudanças estruturais, mesmo imbuídas de atores sociais desafiantes.

A cooperação, estruturada na configuração de empreendimentos cooperativos centrais, seria consequência, sob essa perspectiva teórica, das habilidades sociais estratégicas desses líderes (atores sociais hábeis). Fligstein (2007) ressalta que o ator com habilidades sociais estratégicas teria condições de atuar de diversas formas para tornar possível a cooperação - passar a ideia de que eles não estão no controle, definir agendas, isolar grupos divergentes, dentre outros.

O funcionamento do empreendimento cooperativo de segundo grau, em relação à manutenção de seus níveis competitivos, não é algo dado pelo contexto institucional. Não é a natureza do negócio e sua forma estrutural (aumento do poder de barganha, redução nos custos de produção, dentre outros) que tornará suas atividades perenes no mercado. $\mathrm{O}$ funcionamento de uma cooperativa central só obteria resultados econômicofinanceiros satisfatórios, em decorrência da diversidade de relacionamentos inter-relacionados, por vezes conflitantes, pelo "posicionamento dos atores em campos autônomos, relativos e específicos" (HEILBRON et al., 2014, p.5).

Essas formas de atuação e de posicionamento teriam, sobretudo, uma dupla finalidade, contribuir para a cooperação do grupo fazendo com que a cooperativa central consiga a cooperação das cooperativas singulares, tornando o empreendimento competitivo, e ao mesmo tempo, garantir a perpetuação do ator estratégico no poder. Uma vez que, conforme ressalta Ganz (2005, p. 214), as habilidades sociais estratégicas estão relacionadas em "como os atores transladam seus recursos em poder".

O ponto frágil da perspectiva da Teoria dos Campos e da Habilidade Social Estratégica é escassa comprovação empírica, haja vista que seu principal conceituador, o sociólogo Neil Fligstein, reconhecesse a lacuna entre os preceitos teóricos e a comprovação prática mediante pesquisas. Seria, dessa forma, necessário o desenvolvimento de investidas empíricas no âmbito do movimento cooperativista do setor agropecuário, notavelmente em relação às cooperativas de segundo grau, com a finalidade de compreender como atuam, onde se localizam e como se estruturam os atores sociais hábeis nos campos dominantes. 


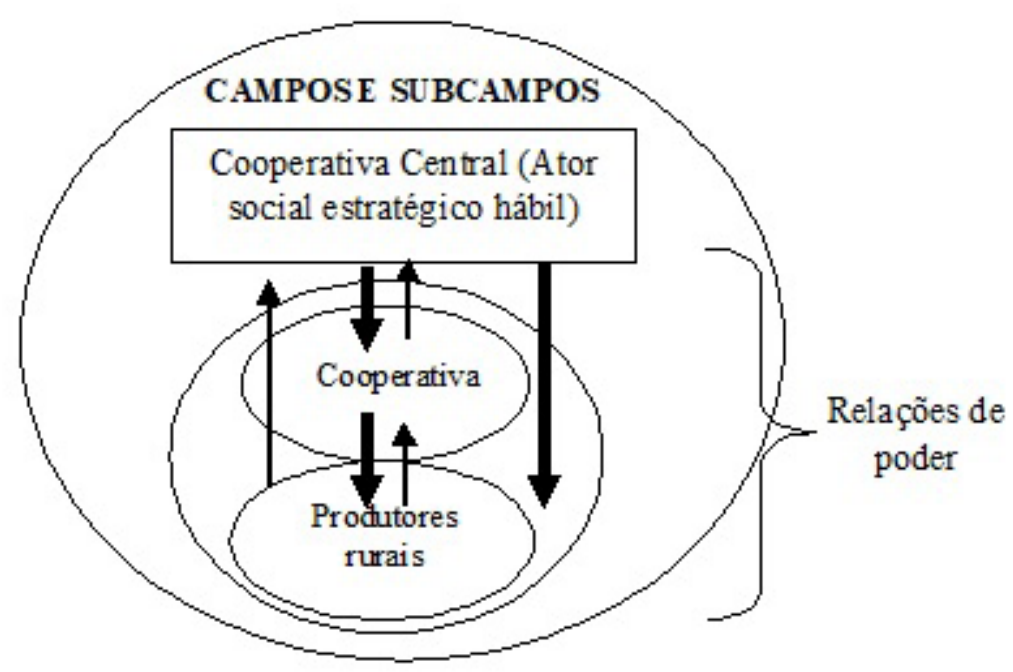

FIGURA 4 - Representação das relações de poder no campo e nos subcampos que envolvem o empreendimento cooperativo integralizado

Fonte: elaboração própria, a partir de Fligstein, 2007

\section{APONTAMENTOS FINAIS}

A partir de um ponto comum, relativo ao preceito da Sociologia Econômica, que nas palavras de Heibron et al. (2014) é sumarizado no ato em que as ações de atores econômicos, como é o caso das cooperativas centrais, estão imersos em sistemas sociais relacionais, torna-se conclusiva a afirmativa de que há diferentes pressupostos teóricos nas três diferentes bases epistemológicas conformativas a referida perspectiva. Essas diferenças passaram a explicar a busca da possibilidade de níveis competitivos satisfatórios à sustentabilidade do empreendimento cooperativo agropecuário centralizado na forma pela qual são percebidas as ligações em relação aos comportamentos dos atores e os resultados dessas ações na estrutura do negócio.

Enquanto a ECT e a NEI se concentram em relações dinâmicas binárias (comprador-vendedor, por exemplo) mediante a formalização de contratos, preocupando-se com a redução dos custos para os diferentes atores, o processo de integralização, visto pela perspectiva das redes, defende benefícios para além dos atores individuais (SMITH, 2003). A teoria da rede social enfatiza que as relações estão submissas ao que Bijman (2005) denomina de mecanismo social (normas e vínculos sociais). Dessa forma, muito além de simples contratos, a relação de integralização em cooperativas agropecuárias seria perene, e almejaria resultados econômico-financeiros satisfatórios, a partir da imersão dos diversos atores nela envolvidos.
Assim, características sociais como confiança, altruísmo e a reciprocidade seriam as variáveis garantidoras do funcionamento do negócio cooperativo.

Ademais, a perspectiva dos Campos e das Habilidades Sociais, contestando as perspectivas anteriores, advoga que o cenário de cooperativas centrais funcionaria a níveis competitivos iguais ou superiores àqueles de organização não cooperativas, na medida em que os atores sociais em posições estruturais representativas de poder atuem, intencionalmente (de forma estratégica) na manutenção da estrutura favorável ao funcionamento do negócio. Conforme se percebe, há, sob essa perspectiva, uma intensa relação entre agente e estrutura.

É preciso ressaltar, contudo, que as três perspectivas adotadas apresentam pontos explicativos favoráveis e desfavoráveis, no âmbito teórico, para análise do contexto de estruturação de cooperativas de segundo grau. Caberá ao pesquisador identificar a raiz epistemológica, dentre aquelas aqui abordadas, mais apropriadas à forma de análise pela qual o problema de pesquisa será delimitado.

\section{REFERÊNCIAS}

AHUJA, G. Collaboration networks, structural holes, and innovation: A longitudinal study. Administrative Science Quarterly, v. 45, n. 3, p. 425-455, 2000. 
AMODEO, N. B. P. As Cooperativas Agroindustriais e os Desafios da Competitividade. 1999. $259 \mathrm{f}$. Tese de Doutorado (Programa de Pós-Graduação em Desenvolvimento, Agricultura e Sociedade) Universidade Federal Rural do Rio de Janeiro, Rio de Janeiro.

AMODEO, N. B. P. As cooperativas e os desafios da competitividade. Estudos Sociedade e Agricultura (UFRJ), Rio de Janeiro, v. 17, n.17, p. 119-144, 2001.

ANTONIALLI, L. M. Influência da mudança de gestão nas estratégias de uma cooperativa agropecuária. Revista de Administração Contemporânea, v. 4, n. 1, p. 135159, 2000.

BECKERT, J. What is sociological about economic sociology? Uncertainty and the embeddedness of economic action. Theory and Society, v. 25, n. 6, p. 803-840, 1996.

BIALOSKORSKI NETO, S. Cooperativas: um ensaio sobre eficiência econômica, contratos e fidelidade. In: BIALOSKORSKI NETO, S. Workshop Internacional de Tendências do Cooperativismo. Ribeirão Preto: FEARP/ USP, 2008, p. 85-93.

BIALOSKORSKI NETO, S. Economia e Gestão de Organizações Cooperativas. São Paulo: Atlas. 2012. $231 \mathrm{p}$.

BIJMAN, J. Network and hierarchy in Dutch cooperatives: a critical analysis. International Journal of Co-operative Management, v. 2, n. 2, p. 16-24, 2005.

BOLAND, M.; HOGELAND, J.; MCKEE, G. Current issues in strategy for agricultural cooperatives. Choices, v. 26, n. 3, 2011. Disponível em: < http://www. choicesmagazine.org/choices-magazine/theme-articles/ critical-issues-for-agricultural-cooperatives/currentissues-in-strategy-for-agricultural-cooperatives $>$. Acesso em: 27 jun. 2014.

BOURDIEU, P. The Forms of capital. In: RICHARDSON, J. G. (ed.) Handbook of theory and research for the Sociology of Education. Nova Iorque: Greenwood Press, 1986. p.241-258.

BOURDIEU, P. Razões práticas: sobre a teoria da ação. Papirus Editora, 1996.
BURT, R. S. The social capital of structural holes. In: GUILlen, M. F. et al. (Eds). New Directions in Economic Sociology, p. 201-247, 2001.

CHADDAD, F. R. Cooperativas no Agronegócio do Leite: Mudanças Organizacionais e Estratégicas em Resposta à Globalização. Organizações Rurais e Agroindustriais, v. 9, p. 69-78, 2007.

CHADDAD, F.; ILIOPOULOS, C. Control rights, governance, and the costs of ownership in agricultural cooperatives. Agribusiness, v. 29, n. 1, p. 3-22, 2013.

COASE, R. H. The nature of the firm. Economica, v. 4, n. 16, p. $386-405,1937$.

COOK, M. L. The future of US agricultural cooperatives: A neo-institutional approach. American Journal of Agricultural Economics, v. 77, n. 5, p. 1153-1159, 1995.

CRÚZIO, H. O. Por que as cooperativas agropecuárias e agroindustriais brasileiras estão falindo? Revista de Administração de Empresas, v. 39, n. 2, p. 18-26, 1999.

EMELIANOFF, I. V. Economic Theory of Cooperation: Economic structure of cooperative organizations. Edwards, 1942.

FLIGSTEIN, N. Habilidade social e a Teoria dos Campos. Revista de Administração de Empresas, v. 47, n. 2, p. 61-80, 2007.

FLIGSTEIN, N.; MCADAM, D. A Theory of Fields. New York: Oxford University Press, 2012. 238 p.

GALERANI, J. Formação, estruturação e implementação de aliança estratégica entre empresas cooperativas. RAE eletrônica, v. 2, n. 1, 2003.

GANZ, M. Why David sometimes wins: Strategic capacity in social movements. In: MESSICK, D. M.; KRAMER, R. M. (Eds.). Psychology of Leadership: New Perspectives and Research, p. 209 - 238, 2005.

GIMENES, R. M. T.; GIMENES, F. M. P. Agronegócio cooperativo: a transição e os desafios da competitividade. Redes, v. 12, n. 2, p. 92-108, 2007. 
GRANOVETTER, M. The old and the new economic sociology: A history and an agenda. In: ROBERTSON, A. F.; FRIEDLAND, R. Beyond the marketplace: Rethinking economy and society, p. 89-112, 1990.

GRANOVETTER, M. The economic sociology of firms and entrepreneurs. Entrepreneurship: The social science view, p. 244-275, 2000.

GULATI, R.; GARGIULO, M. Where do interorganizational networks come from? American Journal of Sociology, v. 104, n. 5, p. 1439-1493, 1999.

HALL, P. A.; TAYLOR, R. C. R. Political science and the three new institutionalisms. Political Studies, v. 44, n. 5, p. 936-957, 1996.

HARTE, L. N. Creeping Privatisation of Irish Cooperatives: A Transaction Cost Explanation. In: NILSSON, J.; DIJK, G. V. (Eds.). Strategies and structures in the Agro-food industries. Netherlands: Van Gorcum \& Comp., 1997, p. 31-53.

HEILBRON, J. et al. The origins and early diffusion of "shareholder value" in the United States. Theory and Society, v, 43, n.1, p. 1-22, 2014.

JARZABKOWSKI, P.; FENTON, E. Strategizing and organizing in pluralistic contexts. Long Range Planning, v. 39, n. 6, p. 631-648, 2006.

LEVI, Y.; DAVIS, P. Cooperatives as the "Enfants Terribles"of Economics: Some Implications for the Social Economy. The Journal of Socio-Economics, v. 37, n. 6, p. $2178-2188,2008$.

LING, K. C. Cooperative theory, practice, and financing: A Dairy Cooperative case study. USDA - Research Report 221. Washington: USDA, 2011. Disponível em: < http://www.rurdev.usda.gov/supportdocuments/RR221. pdf $>$. Acesso em: 27 jun. 2014.

MACEDO, A. S. et al. O papel da comunicação na articulação dos diferentes níveis de organização no modelo central-singular de cooperativas. Bahia Análise \& Dados, v.23, p. 89-105, 2013.

MAGALHÃES, R. S. Habilidades sociais no mercado de leite. Revista de Administração de Empresas, v. 47, n. 2, p. 1-11, 2007.
MENARD, C. Cooperatives: hierarchies or hybrids? In: KARANTININIS, K.; NILSSON, J. (Eds.). Vertical Markets and Cooperative Hierarchies. Netherlands: Springer, 2006. 1-17 p.

NASSAR, A. M.; ZYLBERSZTAJN, D. Associações de interesse no agronegócio brasileiro: análise de estratégias coletivas. Revista de Administração, v.39, n. 2, p. 141152, 2004.

NILSSON, J. et al. Are large and complex agricultural cooperatives losing their social capital?. Agribusiness, v. 28, n. 2, p. 187-204, 2012.

NOVKOVIC, S.; HOLM, W. Co-operative networks as a source of organizational innovation. The International Journal of Co-operative Management, v. 6, n. 11, p.51$60,2012$.

ÖSTERBERG, P.; NILSSON, J. Members' perception of their participation in the governance of cooperatives: the key to trust and commitment in agricultural cooperatives. Agribusiness, v. 25, n. 2, p. 181-197, 2009.

PORTER, M. E. Vantagem competitiva: criando e sustentando um desempenho superior. 4 ed. Rio de Janeiro: Campus, 1992.

PORTES, A. Social capital: Its origins and applications in modern sociology. Annual Review of Sociology, v. 24, p. 1 - 24, 1998.

SACOMANO NETO, M.; TRUZZI, O. M. S. Redes, campos e instituições: constituindo uma agenda para a análise das relações entre organizações. Gestão e Sociedade, v. 3, n. 6, p. 230-253, 2010.

SMITH, S. C. Network externalities and co-operative networks: stylized facts and theory. In: SUN, L. (Ed.). Ownership and Governance of Enterprises Recent innovative developments. New York: Palgrave MacMillan, 2003, p.181-201.

SOUZA, D. N. et al. A comunicação na articulação agroindustrial no modelo federado de cooperativas. Por Extenso: Boletim de Pesquisas do Programa de Pós-Graduação em Extensão Rural, n. 3, p. 2833, 2011. 
THELEN, K. Historical institutionalism in comparative politics. Annual review of political science, v. 2, n. 1, p. 369-404, 1999.

THÉRET, B. As instituições entre as estruturas e as ações. Lua nova, v. 58, p. 225-254, 2003.

TORGERSON, R. E. A Critical Look at New-Generation Cooperative. Rural Cooperatives, v. 68, n. 1, p. 15-19, 2001 .

VALADARES, J. H. A moderna administração de cooperativas. In: MOURA, A. D.; SILVA JÚNIOR, A. G.; BAIÃO, L. B. Agricultura familiar no agronegócio. Viçosa, MG: UFV, 2005, v. 1, p. 205-214.

VALADARES, J. H. Estrutura e estratégia institucional: formação de campo organizacional e isomorfismo no cooperativismo de crédito rural de Minas Gerais. 126f. Tese (Doutorado em Ciências Sociais). Programa de Pós-Graduação de Ciências
Sociais em Desenvolvimento, Agricultura e Sociedade, UFRRJ, Seropédica, 2003.

VALE, G. M. V.; AMÂNCIO, R.; LIMA, J. B. Criação e gestão de redes: uma estratégia competitiva para empresas e regiões. Revista de Administração da Universidade de São Paulo, v. 41, n. 2, 2006.

WILliAMSON, O. E. Comparative Economic Organization: The Analysis of Discrete Structural Alternatives. Administrative Science Quarterly, v.36, jun., p. 269-296, 1991.

ZYLBERSZTAJN, D. Organização de cooperativas: desafios e tendências. Revista de Administração, v. 29, n. 3, p. 23-32, jul./set. 1994.

ZYLBERSZTAJN, D. Quatro estratégias fundamentais para cooperativas agrícolas. In: BRAGA, M. J.; REIS, B. S. (Org.). Agronegócio cooperativo-reestruturação e estratégias. Viçosa: Suprema, 2002, p. 55-75. 